\title{
Acute care assessment of older adults living with frailty
}

\author{
Terence J Quinn chief scientist office and stroke association senior clinical lecturer ${ }^{1}$, Simon P \\ Mooijaart director ${ }^{2}$, Katie Gallacher stroke association senior clinical lecturer in primary care ${ }^{3}$, \\ Jennifer K Burton SCREDS clinical lecturer in geriatric medicine ${ }^{4}$
}

${ }^{1}$ Institute of Cardiovascular and Medical Sciences, University of Glasgow, Glasgow, UK; ${ }^{2}$ Institute for Evidence Based Medicine in Old Age, Leiden University Medical Centre, Leiden, Netherlands; ${ }^{3}$ Institute of Health and Wellbeing, University of Glasgow, Glasgow, UK; ${ }^{4}$ Institute of Cardiovascular and Medical Sciences, University of Glasgow, Glasgow, UK

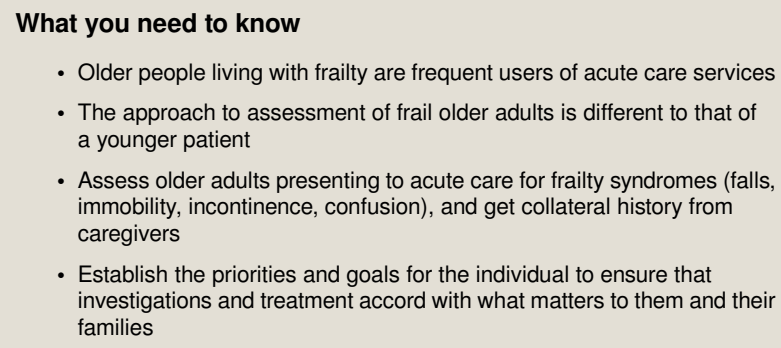

- Establish the priorities and goals for the individual to ensure that investigations and treatment accord with what matters to them and their families

Older adults living with frailty are frequent users of emergency services. Acute care settings are stressful for patients, care givers, and staff. The focus on prompt assessment, rapid decision making, and constant patient flow make the environment less suited to the older adult. We suggest an approach for clinicians to assess older adults living with frailty who present to acute care settings such as emergency departments, medical units, or out of hours general practice. Our approach is evidence based where possible but mindful of time and resource constraints. ${ }^{12}$ We focus on assessment as early recognition of frailty and accompanying problems facilitates appropriate onward referral and management.

\section{What is frailty and why does it matter?}

Frailty is something all clinicians recognise, but there is little consensus on its definition. ${ }^{3}$ It can be defined by characteristics such as gait speed and grip strength, ${ }^{4}$ or described as an accumulation of age related diagnoses, symptoms and problems. ${ }^{5}$ Both models share a core concept of increased risk of adverse outcomes from illness.

Observational registries suggest that, in general, older adults tend to be more unwell on presentation, have longer hospital stays, and poorer outcomes. ${ }^{67}$ A systematic review (26 studies) of older adults discharged from emergency departments reported readmission rates as high as $40 \%$ at 6 months. ${ }^{8}$ These readmissions may represent unresolved medical issues, failure of community support, or both. Regardless, data suggest the potential to improve outcomes following acute presentations. There are instruments that screen for frailty and identify those at risk of poor outcomes. Systematic reviews note that these instruments have limited prognostic accuracy and are not always feasible for use in acute care. ${ }^{910}$ However, the Rockwood Frailty Scale $^{11}$ may help triage patients requiring specialist older adult care. If nothing else, the tools act as a prompt for the clinician to ask: do I need to tailor my approach and does this person need specialist, multidisciplinary input? ${ }^{12}$

\section{How does the approach to assessment differ in frailty?}

A broader approach is needed for diagnosis in patients with frailty (box 1). Presentations of acute illness tend to be non-specific, treatments may need to be modified, and prognosis will differ. Patients with frailty often have several issues requiring assessment, against a background of complex comorbidity and social support. Acute care is often not well suited to older adults with cognitive or sensory problems. If possible, perform assessments in a quiet (or quieter) room away from the busy main assessment area. Talk at a speed and volume that allows the person to understand and involve care givers as necessary. Sometimes simple measures can make the consultation easier for both clinician and patient, for example, does the patient have a hearing aid and is it turned on? ${ }^{13}$ 
Box 1: Advantages of a tailored assessment of older adults Diagnostic-In older adults, disease often presents non-specifically. Screening for the various frailty syndromes (falls, incontinence, confusion) Screening for the various frailty
is likely to have a high yield

Prognostic-Screening for frailty syndromes can tell you how the person may respond to treatment, or about their future healthcare needs. For example, a history of falling is one of the strongest predictors of future (preventable) falls

Legal—Cognitive screening tests can inform an assessment of the patient's capacity to consent to medical intervention

Documentary monitoring-A baseline assessment for pressure sores, bruising consistent with non-accidental injury, oropharyngeal dysphagia, etc, may help assess for change in the patient and will be useful if there is a complaint or investigation

Satisfaction-Both patients and staff can be dissatisfied with how older adults are managed in acute care; a tailored approach, which is age appropriate, may be more clinically useful and ultimately more satisfying for the practitioner

Figures 1 and 2 provide key aspects to cover on initial evaluation in the acute care setting. These assessments do not need to be completed in one session and assessment should be shared between doctors, nurses, and other members of the multidisciplinary team. Some of the finer details listed in table 1 can be obtained after the initial assessment.

Once frailty is recognised, onward referral for comprehensive geriatric assessment (CGA) should be considered. CGA is a specialist, multidimensional and interdisciplinary process "focused on determining a person's medical, psychosocial, and functional capabilities in order to develop a coordinated and integrated plan for treatment and follow-up." 14

Findings from a systematic review of 29 randomised controlled trials support the efficacy of CGA in dedicated older adult wards. ${ }^{15}$ CGA in the emergency department is less established, although there are reports of successful implementation. ${ }^{16}{ }^{17}$ Having multidisciplinary staff trained to meet the care needs of older adults in age appropriate acute care environments is associated with better outcomes. ${ }^{18}$ Full CGA may not be feasible in certain acute settings because of time or lack of a specialist team. However, clinicians in acute care should be able to recognise frailty and initiate onward referral to specialist teams. Delivery of CGA is not confined to secondary care. The initial assessment should determine if the patient is suitable for discharge to community, multidisciplinary teams who can continue assessment and rehabilitation. ${ }^{19}$

\section{What should I cover on initial evaluation?}

The initial description of symptoms (before it is altered by repeated telling) is crucial and should be recorded verbatim. These details can, for example, subsequently help to distinguish falls from syncope or seizure.

Look for underlying problems that precipitated presentation and coexisting clinical and social factors that may complicate management. In people living with frailty, more than one problem can cause functional decline. Try to form a problem list rather than a single unifying diagnosis.

We would recommend, as a minimum, assessing for

Frailty syndromes-Sometimes the cause of the older adult's presentation is obvious, but often they tend not to present with textbook signs and symptoms. Rather, presentation with the frailty syndromes, namely, falls, incontinence, immobility and/or confusion is the final common pathway of multiple disease presentations. ${ }^{20}$ It can be useful to ask yourself "if this person were 20 would I have expected them to fall/become incontinent/become confused?" Frailty is rarely the sole reason for admission; an underlying medical problem is usually the precipitant to presentation. The use of labels such as "social admission" with no attempt at further assessment is unhelpful and potentially dangerous.

Medication-Polypharmacy is the norm in people living with frailty and adverse effects of medications are a common reason for hospital admission. ${ }^{21}$ Obtain an accurate medication list, including over-the-counter preparations, and ask about compliance with these treatments. Tools are available to highlight medications that are potentially inappropriate or that should be prioritised in frailty. ${ }^{22-24}$

Function-Acute illness may present as a change in function, for example deterioration in mobility or difficulty with self care and toileting. Assessment as part of general history taking is usually sufficient, although short structured assessments of function are available. ${ }^{25}$ Much can be gained from assessing the patient's gait so, if safe to do so, observe the patient mobilising. ${ }^{13}$ Functional ability is often the criterion that determines whether a patient can be discharged home or if they require admission for CGA. Assessment by allied health professionals in the acute care setting may be needed before discharge.

Cognition-Assessing cognition in acute illness is a trade off between accuracy and feasibility. Unstructured, subjective assessment misses important problems, while detailed, neuropsychological assessments are not practical. ${ }^{2627}$ Brief screening tools can assess general cognition and delirium, for example the 4 A Test is accurate and feasible for use in acute illness. ${ }^{28}$ Even with specific tests, delirium is easily missed. If an older adult appears drowsy, they may have delirium. In addition to testing a patient's cognition at time of presentation, it is also often useful to determine change in cognition over time. Short questionnaires and single questions ${ }^{2930}$ asked of someone that knows the patient can capture this cognitive trajectory.

Investigations-Single measures such as temperature, blood pressure, and pulse may be misleading in frailty. ${ }^{31}$ Trends are typically more useful. Test for orthostatic hypotension as it is common and often associated with falls. ${ }^{32}$ Routine urinalysis is not sensitive nor specific for diagnosing disease in older adults. ${ }^{33}$

Collateral history and caregivers- $A$ frequent challenge in assessing older adults is judging how different they are from baseline. Contacting family, carers, or any other collateral information sources takes time initially, but may avoid an unnecessary admission or highlight functional and cognitive change that triggers further assessment. Accessing medical records, prescriptions, and phone calls to primary care can give further information that will make the assessment more efficient.

Caregivers commonly report that their knowledge of the patient is not given sufficient attention in the acute care setting. ${ }^{34}$ They can often provide information on a patient's frailty history, ie, the functional impact of illness over time. In some countries, carers can apply for legal powers to assist with healthcare decisions. If so, ask if anyone has such powers if the patient may be unable to make informed choices.

Ask the carer how they are doing. If care givers are struggling, offer access to agencies that can help. Providing care affects psychological health. ${ }^{35}$ Some screening tools for assessing care giver burden are available. ${ }^{36}$

Establish the person's priorities-Early in the process, try to establish the person's priorities. The emergency medicine mantra of "treat first what kills first," may be inappropriate for people living with frailty. To avoid death may not be the primary concern and invasive treatments may conflict with priorities such as remaining independent and living or dying at home. Helpful questions include: "What matters to you and what 
information do you need?" ${ }^{37}$ These questions ensure a focus on the person and not just their presenting symptoms.

Ask the person and their family if an advance care plan exists and if they have specific wishes about their care that should be recorded. The process of advance care planning is helpful in frailty where changes in health status are expected. It includes discussion and documentation of how clinical deterioration should be handled, for example wishes around cardiopulmonary resuscitation.

\section{Sources and selection criteria}

This review is based on the authors' clinical and research experience and is informed by a search of published literature. We searched electronic databases (Medline and Embase) from 2014 to January 2018, using the following keywords: "aged" OR "aged, over 80," "geriatric assessment," and "acute" and selected those titles pertinent to the acute care settings. We searched key reference works and national and international guidelines for relevant papers, and gave particular attention to systematic reviews. To ensure that our suggestions are credible and practical, draft versions were reviewed by older adults and staff from several acute care settings across the UK (see acknowledgments).

\section{Questions for future research}

- Which screening tools have greatest utility for initial assessment and further management of frail older adults?

- How can older adult screening assessments be implemented in acute care to increase uptake?

- What outcomes are important to older adults presenting to acute care services and how can these be measured?

- Can routine screening of caregivers for psychological problems improve care outcomes?

\section{Additional educational resources}

The following resources are all free, although they require registration to access certain content.

- Geriatric Emergency Medicine (GEM). This North American group provides podcast learning and discussion materials around older adults and the emergency department. https://gempodcast.com

- e-Learning on Geriatric Emergency Medicine. This Canadian web resource offers tutorials and other learning materials on older adults and emergency care. https://geri-em.com/

- The Royal College of Emergency Medicine has a regular podcast with occasional materials on older adults, eg, this podcast on cognitive assessment: https://www.rcemlearning.co.uk/foamed/january-2018/

- American College of Emergency Physicians. Geriatric Emergency Department Guidelines: https://www.acep.org/geriEDguidelines/ and videos https://www.acep.org/Clinical-Practice-Management/GeriatricVideos/

- The British Geriatric Society has a variety of online resources around older adults in acute care, eg: Quality Care for Older People with Urgent \& Emergency Care Needs 2012. http://www.bgs.org.uk/campaigns/ silverb/silver_book_complete.pdf

- Royal College of Physicians. Acute medical care for older people: https: //www.rcplondon.ac.uk/file/1197/download?token=-tA0spuS

\section{Information resources for patients}

Alzheimer's Society provides information on navigating healthcare systems if you or someone you look after has dementia: Help with Dementia Care: https://www.alzheimers.org.uk/info/20046/help_with_dementia_care

Age UK provides a variety of free resources, including general information and advice: https://www.ageuk.org.uk/information-advice/ and specialist reports, eg, reports of older adults' experiences of hospital admission and readmission: https://www.ageuk.org.uk/globalassets/age-uk/documents/ information-guides/ageukig07_your_hospital_stay_inf.pdf and https://www. ageuk.org.uk/documents/en-gb/for-professionals/research/emergency readmission_older_peoples_experiences.pdf?dtrk=true

\section{Education into practice}

How do you evaluate older adults for frailty?

How do you inquire about cognition and functional ability when you assess older adults in acute care?

\section{How patients were involved in the creation of this article}

We consulted older adults who have used acute care services about relevant topics to include, and they also read and commented on the article before publication. We also sought views of staff working in older adult and emergency department services. These comments helped us to ensure the article and its recommendations were acceptable to frontline clinicians and service users.

Competing interests The $B M J$ has judged that there are no disqualifying financial ties to commercial companies. The authors declare the following other interests: TQ and KG are supported by Stroke Association/ Chief Scientist Office Clinical Lectureships. SPM receives support from Institute for Evidence Based Medicine in Older Age. JKB is supported by the Scottish Clinical Research Excellence Development Scheme funded by NHS Education for Scotland.

Further details of The BMJ policy on financial interests is here: https://www.bmj. com/about-bmj/resources-authors/forms-policies-and-checklists/declarationcompeting-interests

All authors contributed to researching the manuscript, drafting and editing and obtaining expert review from patients, carers and other stakeholders.

Provenance and peer review: commissioned, based on an idea from the author; externally peer reviewed.

Aguayo GA, Donneau AF, Vaillant MT, etal . Agreement between 35 published frailty scores in the general population. Am J Epidemiol 2017;186:420-34 10.1093/aje/kwx061 28633404

2 Fried LP, Tangen CM, Walston J, etal. Cardiovascular Health Study Collaborative Research Group. Frailty in older adults: evidence for a phenotype. J Gerontol A Biol Sci Med Sci 2001;56:M146-56. 10.1093/gerona/56.3.M146 11253156

3 Rockwood K, Stadnyk K, MacKnight C, McDowell I, Hébert R, Hogan DB. A brief clinical instrument to classify frailty in elderly people. Lancet 1999;353:205-6. 10.1016/S0140-6736(98)04402-X 9923878

4 Aminzadeh F, Dalziel WB. Older adults in the emergency department: a systematic review of patterns of use, adverse outcomes, and effectiveness of interventions. Ann Emerg Med 2002;39:238-47. 10.1067/mem.2002.121523 11867975

5 Geriatric Emergency Medicine. In: Nickel C, Bellou A, Conroy S, eds. Springer, 2018.

6 Banerjee J, Conroy S. The silver book: quality care for older people with urgent and emergency care needs. British Geriatric Society 2012. http://www.bgs.org.uk/campaigns/ silverb/silver_book_complete.pdf.

7 Gruneir A, Silver MJ, Rochon PA. Emergency department use by older adults: a literature review on trends, appropriateness, and consequences of unmet health care needs. Med Care Res Rev 2011;68:131-55. 10.1177/1077558710379422 20829235

8 McCusker J, Verdon J. Do geriatric interventions reduce emergency department visits? A systematic review. J Gerontol A Biol Sci Med Sci 2006;61:53-62. 10.1093/gerona/61.1.53 16456194

9 Elliott A, Hull L, Conroy SP. Frailty identification in the emergency department-a systematic review focussing on feasibility. Age Ageing 2017:46:509-13. 10.1093/ageing/afx019 28200012

10 Wou F, Gladman JR, Bradshaw L, Franklin M, Edmans J, Conroy SP. The predictive properties of frailty-rating scales in the acute medical unit. Age Ageing 2013;42:776-81. 10.1093/ageing/aft055 23666406

11 Rockwood K, Song X, MacKnight C, etal . A global clinical measure of fitness and frailty in elderly people. CMAJ 2005;173:489-95. 10.1503/cmaj.050051 16129869

12 Pugh RJ, Ellison A, Pye K, etal . Feasibility and reliability of frailty assessment in the critically ill: a systematic review. Crit Care 2018;22:49. 10.1186/s13054-018-1953-9 29478414

13 Quinn TJ, McArthur K, Ellis G, Stott DJ. Functional assessment in older people. BMJ 2011;343:d4681. 10.1136/bmi.d4681 21859792

14 Parker SG, McCue P, Phelps K, etal . What is Comprehensive Geriatric Assessment (CGA)? An umbrella review. Age Ageing 2018;47:149-55. 10.1093/ageing/afx166 29206906

15 Ellis G, Gardner Mike, Tsiachristas A, et al Comprehensive geriatric assessment for older adults admitted to hospital. Cochrane Database Syst Rev 2017;9:CD006211.pub3.

16 Conroy SP, Ansari K, Williams M, etal . A controlled evaluation of comprehensive geriatric assessment in the emergency department: the 'Emergency Frailty Unit'. Age Ageing 2014:43:109-14. 10.1093/ageing/aft087 23880143

17 Graf CE, Zekry D, Giannelli S, Michel JP, Chevalley T. Efficiency and applicability of comprehensive geriatric assessment in the emergency department: a systematic review. Aging Clin Exp Res 2011;23:244-54. 10.1007/BF03337751 20930499

18 Hogan DB, Maxwell CJ, Afilalo J, etal . A scoping review of frailty and acute care in middle-aged and older individuals with recommendations for future research. Can Geriatr J 2017:20:22-37. 10.5770/cgj.20.240 28396706

19 Offord N, Harriman P, Dwones T. Discharge to assess: transforming the discharge process of frail older patients. Future Healthcare $J$ 2017;4:30-2

20 The Challenge of Geriatric Medicine. Isaacs B. Oxford University Press, 1992. 
21 Lavan AH, Gallagher P, Parsons C, O'Mahony D. STOPPFrail (Screening Tool of Older Persons Prescriptions in Frail adults with limited life expectancy): consensus validation. Age Ageing 2017;46:600-7.28119312

22 Gallagher P, Ryan C, Byrne S, Kennedy J, O’Mahony D. STOPP (screening tool of older person's prescriptions) and START (screening tool to alert doctors to right treatment). Consensus validation. Int J Clin Pharmacol Ther 2008;46:72-83. 10.5414/CPP46072 18218287

23 Wehling M, Collins R, Gil VM, etal. Appropriateness of oral anticoagulants for the long-term treatment of atrial fibrillation in older people: results of an evidence-based review and international consensus validation process (OAC-FORTA 2016). Drugs Aging 2017;34:499-507. 10.1007/s40266-017-0466-6 28493216

24 Maclsaac RL, Ali M, Taylor-Rowan M, Rodgers H, Lees KR, Quinn TJVISTA Collaborators. Use of a 3-item short-form version of the Barthel Index for use in stroke: systematic review and external validation. Stroke 2017;48:618-23. 10.1161/STROKEAHA.116.014789 28154094

25 Lees RA, Hendry Ba K, Broomfield N, Stott D, Larner AJ, Quinn TJ. Cognitive assessmen in stroke: feasibility and test properties using differing approaches to scoring of incomplete items. Int J Geriatr Psychiatry 2017;32:1072-8. 10.1002/gps.4568 27526678

26 Quinn TJ, Elliott E, Langhorne P. Cognitive and mood assessment tools for use in stroke. Stroke 2018:49:483-90. 10.1161/STROKEAHA.117.016994 29284733

27 Bellelli G, Morandi A, Davis DHJ, etal . Validation of the 4AT, a new instrument for rapid delirium screening: a study in 234 hospitalised older people. Age Ageing 2014;43:496-502. 10.1093/ageing/afu021 24590568

28 Harrison JK, Fearon P, Noel-Storr AH, McShane R, Stott DJ, Quinn TJ. Informant Questionnaire on Cognitive Decline in the Elderly (IQCODE) for the diagnosis of dementia within a secondary care setting. Cochrane Database Syst Rev 2015;10:CD010772.25754745

29 Hendry K, Hill E, Quinn TJ, Evans J, Stott DJ. Single screening questions for cognitive impairment in older people: a systematic review. Age Ageing 2015;44:322-6. 10.1093/ageing/afu167 25385272
30 Downey CL, Tahir W, Randell R, Brown JM, Jayne DG. Strengths and limitations of early warning scores: A systematic review and narrative synthesis. Int $J$ Nurs Stud 2017;76:106-19. 10.1016/.j.jnurstu.2017.09.003 28950188

31 Heldeweg MLA, Jorge PJF, Ligtenberg JJM, Ter Maaten JC, Harms MPM. Orthostatic blood pressure measurements are often overlooked during the initial evaluation of syncope in the emergency department. Blood Press Monit 2018;23:294-6.30161039

32 Schulz L, Hoffman RJ, Pothof J, Fox B. Top ten myths regarding the diagnosis and treatment of urinary tract infections. J Emerg Med 2016;51:25-30. 10.1016/j.jemermed.2016.02.009 27066953

33 Grief CL. Patterns of ED use and perceptions of the elderly regarding their emergency care: a synthesis of recent research. J Emerg Med 2007;22:1527-31.

34 Ankuda CK, Maust DT, Kabeto MU, McCammon RJ, Langa KM, Levine DA. Association between spousal caregiver well-being and care recipient healthcare expenditures. J Am Geriatr Soc 2017:65:2220-6. 10.1111/jgs.15039 28836269

35 Bédard M, Molloy DW, Squire L, Dubois S, Lever JA, O'Donnell M. The Zarit Burden Interview: a new short version and screening version. Gerontologist 2001;41:652-7. 10.1093/geront/41.5.652 11574710

36 ALLIANCE Health and Social Care Alliance Scotland, Dementia Carer Voices. Rights and the carer voice: leading change--transforming care: 5 steps to change. 2017. https: //www.alliance-scotland.org.uk/wp-content/uploads/2017/12/ALLIANCE-DCV-5-Steps-tochange-flyer-with-links.pdf.

37 Detering KM, Hancock AD, Reade MC, Silvester W. The impact of advance care planning on end of life care in elderly patients: randomised controlled trial. BMJ 2010;340:c1345. 10.1136/bmj.c1345 20332506

Published by the BMJ Publishing Group Limited. For permission to use (where not already granted under a licence) please go to http://group.bmj.com/group/rights-licensing/ permissions 


\section{Table}

\section{Table 1| Additional physical assessment considerations for older adults with frailty in acute care}

What should I do?

Ensure hearing aids are worn, turned on, and have batteries. Ensure glasses are worn

Inspect the oropharynx.

Consider a bedside water swallow screen for those with advanced frailty, particularly in context of dementia

\section{Assess fluid status and hydration.}

Provide patients with the opportunity to drink and assistance if required

In new incontinence:

palpate for a distended bladder

perform a bladder scan

check for faecal loading

Examine skin and assess pressure area risk.

Document any bruising.

Check for trauma and associated injuries in those who have

fallen or been found on the floor; arranging imaging as

appropriate

Assess gait and inspect feet and footwear

\section{Why may this help?}

Sensory problems are common and represent modifiable risk factors for delirium—simple actions such as these can minimise impairments

Inspection of the oropharynx may reveal barriers to oral diet such as candidiasis, poor dentition, or ill fitting dentures.

Deterioration in swallow can accompany systemic disease. A bedside water swallow screen is simple and can indicate the need for early specialist assessment.

Dry mouth, thirst, and urine colour may be helpful in hydration assessment. However, in an unwell frail individual, a pragmatic approach may be to assume a degree of dehydration unless there is evidence of fluid overload. This is not synonymous with prescribing intravenous fluids: rather, patients should be given opportunity and assistance to drink

Urinary retention secondary to constipation is common and easily treatable baseline. Non-accidental injury is uncommon, but critical to identify and good documentation plus use of medical photography is key

Older people are the largest group experiencing major trauma, most frequently because of falls from standing height. Traumatic brain injury, fracture, and intra-abdominal injury are common sequelae but may be missed by traditional trauma assessment systems

Is footwear appropriate, could toenail overgrowth be contributing to poor mobility, do the heels show areas of pressure damage? 


\section{Figures}

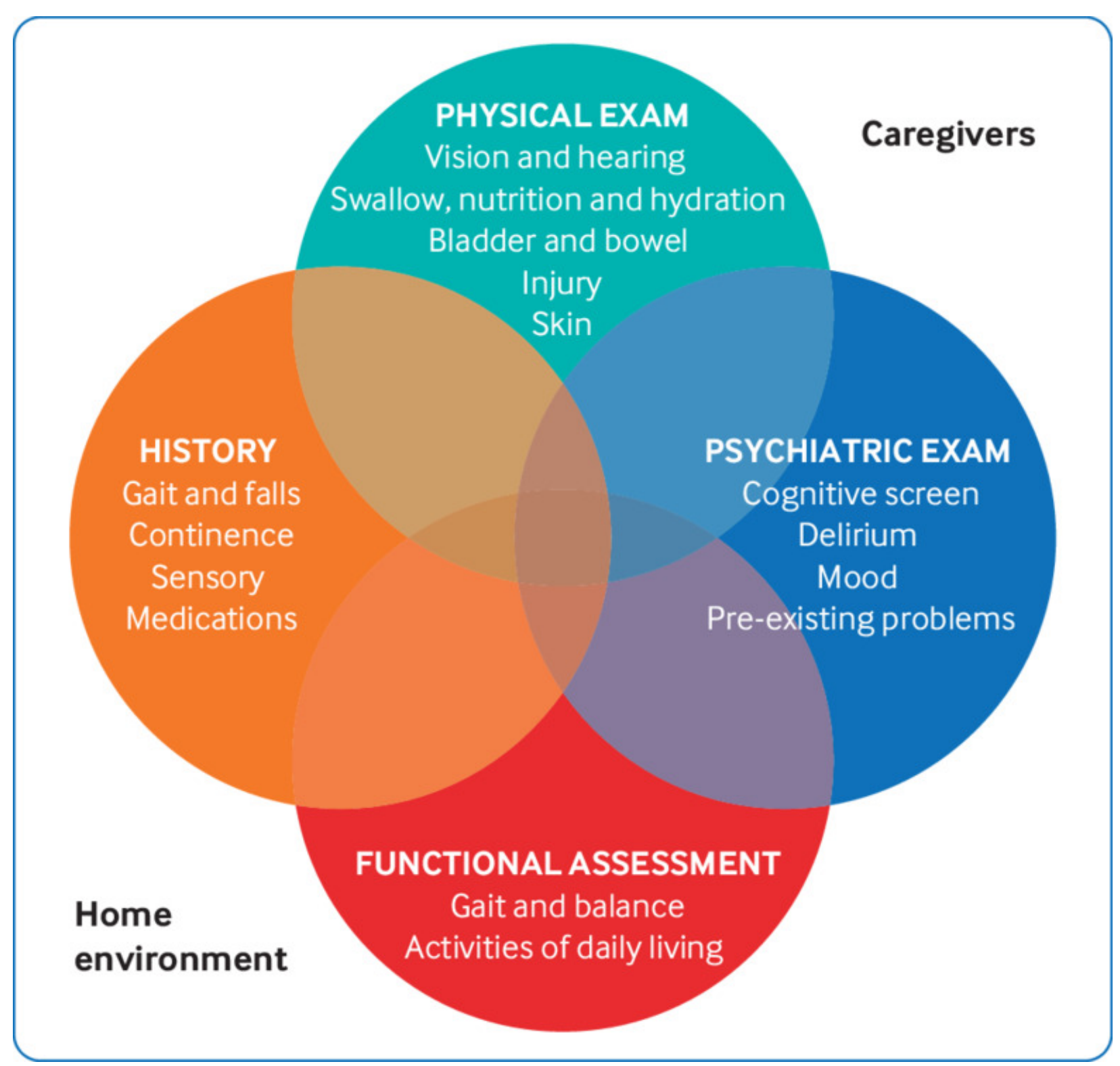

Fig 1 Comprehensive assessment of older adults in acute care settings 


\section{FRAILTY SYNDROMES}

\section{Falls}

Any falls in the past 12 months, including circumstances and associated symptoms? NICE Falls Risk Assessment

\section{Continence}

Any involuntary leakage of urine, including frequency, severity and precipitating factors? International Continence Society

\section{Confusion}

Do you think (name) has been more confused lately?

Single Question in Delirium

\section{Function}

See Barthel Index of activities of daily living below, the items marked were found to be the three most discriminating.

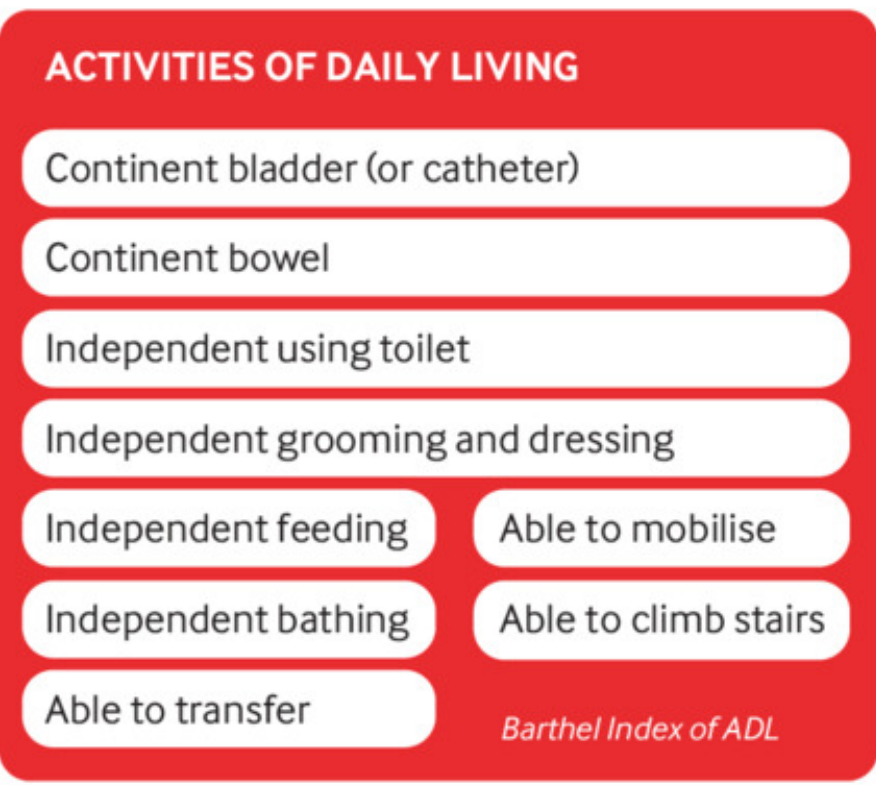

\section{ASSESSMENT OF CARER BURDEN}

Do you feel...

That because of the time you spend with your relative you don't have enough time for yourself?

Stressed between caring for your relative and trying to meet other responsibilities?

Strained when you are around your relative?

Uncertain about what to do about your relative?

Zarit Burden Screening questions

\section{SCREENING TEST FOR COGNITION AND DELIRIUM}

Is patient alert during interview

Complete 4 question AMT (Age, date of birth, place, current year)

Test attention

(Recite months of the year backwards starting at December)

From informant, has there been acute change or fluctuating course of cognition

4 A Test

Fig 2 Some practical tools for assessment of an older adult 